\title{
The impact of the duration of retained placenta on postpartum diseases and culling rates in dairy cows
}

\author{
Tai-Young Hur ${ }^{1, *}$, Young-Hun Jung ${ }^{1}$, Seog-Jin Kang ${ }^{1}$, Chang Yong Choe ${ }^{1}$, Ui-Hyung Kim ${ }^{1}$, \\ II-Sun Ryu', Dong-Soo Son ${ }^{1}$, Sung-Jai Park ${ }^{1}$, Ill-Hwa Kim ${ }^{2}$ \\ ${ }^{I}$ National Institute of Animal Science, RDA, Cheonan 330-801, Korea \\ ${ }^{2}$ College of Veterinary Medicine, Chungbuk National University, Cheongju 361-763, Korea \\ (Received: September 06, 2011, Revised: September 29, 2011; Accepted: September 29, 2011)
}

\begin{abstract}
The objective of this study was to evaluate the duration of retained placenta (RP) on postpartum diseases and culling in dairy cows. Data were collected from 456 Holstein cows between 2008 and 2010. $\mathrm{RP}(\geq 24 \mathrm{~h}$ after parturition) and postpartum diseases were diagnosed by farm managers and a veterinarian according to standardized definitions. The overall incidence rate of RP was $14.0 \%$, and the incidence rate of RP with fourth and higher parity was two times that of cows having offspring for the first time. The duration of RP was 2 to 15 days with a mean of 6.8 days, except for cases of fourth and higher parity which had a mean of 10.5 days. A total of $63 \%$ of cows with RP had postpartum diseases. Among the cows diagnosed with RP, $23.4 \%$ developed metritis, and of those, $35.3 \%$ developed endometritis or pyometra. A total of $25 \%(\mathrm{n}=16)$ cows with RP were culled within 60 days in milk (DIM) and of those culled, $75 \%(n=12)$ had postpartum diseases. These results suggest that RP increases the risk of postpartum diseases such as metritis and mastitis and is a culling hazard up to 60 DIM.
\end{abstract}

Keywords : culling rates, dairy cows, postpartum diseases, retained placenta

\section{Introduction}

Retained placenta (RP) is defined as the retention of the fetal membrane for $>24 \mathrm{~h}[10]$. RP is a serious problem in dairy cows due to resultant direct and indirect economic losses [9]. RP in cattle can lead to adverse health effects that ultimately affect reproductive performance and RP has been associated with an increased risk of pyometra, metritis, ketosis and mastitis $[5,10,14]$. These diseases can lead to decreased fertility, including longer intervals from calving to first service and conception [8, 14].

In the United States, RP was reported to be the third most common health disorder in dairy cows, affecting $7.8 \%$ of lactating cows [7], and was involved in $18.3 \%$ of calvings in Korea [8]. Many reports related to RP etiology, risk factors, reproductive performance, financial effects, and treatments have been published $[2,3,5,8$, $9,14]$, but few papers have addressed the relationship between the duration of RP and postpartum diseases in cows [14].

We hypothesize that dairy cows with RP have more postpartum diseases than those without RP, and that the duration of RP directly effects culling and other diseases. Thus, the objective of this study was to evaluate the interrelationship between the duration of RP and postpartum diseases in periparturient dairy cows.

\section{Material and Methods}

\section{Animals}

A total 456 calving Holstein dairy cows were examined during a three year period at a dairy farm located in Chungnam province, Korea. The health status of the cows was investigated at two-week intervals from five weeks before parturition, at calving, and one week and nine weeks after calving. Data, including history, calving status, and disease information were collected from veterinary records. All cows were raised in free-stall barns with standard Korean feeding practices for dairy

\footnotetext{
*Corresponding author

Tel: +82-41-580-3406, Fax: +82-41-580-3429

E-mail: tyohur@korea.kr
} 
Table 1. Distribution of characteristics of dairy cows with and without retained placenta

\begin{tabular}{|c|c|c|c|c|c|}
\hline \multirow{2}{*}{ Variable } & \multirow{2}{*}{$\begin{array}{l}\text { Cows } \\
\text { No. }(\%)\end{array}$} & \multicolumn{2}{|c|}{ Cows RP (-) } & \multicolumn{2}{|c|}{ Cows RP (+) } \\
\hline & & No. & Percentage & No. & Percentage \\
\hline \multicolumn{6}{|l|}{ Parity } \\
\hline First & $183(40.1)$ & 162 & 88.5 & 21 & 11.5 \\
\hline Second & 127 (27.9) & 109 & 85.8 & 18 & 14.2 \\
\hline Third & $73(16.0)$ & 64 & 87.7 & 9 & 12.3 \\
\hline Fourth or greater & $73(16.0)$ & 57 & 78.1 & 16 & 21.9 \\
\hline Incidence rate & $456(100.0)$ & 392 & 86.0 & 64 & 14.0 \\
\hline \multicolumn{6}{|l|}{ Stillbirth } \\
\hline Yes & $56(12.3)$ & 46 & 82.1 & 10 & 17.9 \\
\hline No & $400(87.7)$ & 346 & 86.5 & 54 & 13.5 \\
\hline \multicolumn{6}{|l|}{ Dystocia } \\
\hline Yes & $100(21.9)$ & 84 & 84.0 & 16 & 16.0 \\
\hline No & $356(78.1)$ & 308 & 86.5 & 48 & 13.5 \\
\hline \multicolumn{6}{|l|}{ Twins } \\
\hline Yes & $12(2.6)$ & 7 & 58.3 & 5 & 41.7 \\
\hline No & 444 (97.4) & 385 & 86.7 & 59 & 13.3 \\
\hline
\end{tabular}

RP: retained placenta.

Table 2. Distribution of dairy cows with retained placenta by parity following on from the duration and mean of placental retention

\begin{tabular}{|c|c|c|c|c|c|c|c|c|c|c|c|}
\hline \multirow{2}{*}{ Parity } & \multirow{2}{*}{ No. of RP } & \multicolumn{9}{|c|}{ Duration (days) } & \multirow{2}{*}{$\begin{array}{c}\text { Mean } \\
\text { (days) }\end{array}$} \\
\hline & & 2 & 3 & 4 & 5 & 6 & 7 & 8 & 9 & $10 \leq$ & \\
\hline 1 & 21 & 3 & & 3 & 4 & 1 & 5 & 4 & & 2 & 6.1 \\
\hline 2 & 18 & & & & 4 & 3 & 4 & 1 & 4 & 2 & 7.4 \\
\hline 3 & 9 & & 2 & & 2 & 1 & & 1 & & 1 & 6.1 \\
\hline 4 & 16 & & 2 & & & 2 & 3 & 2 & 3 & 3 & 10.5 \\
\hline Total & 64 & 3 & 4 & 3 & 10 & 8 & 12 & 9 & 7 & 8 & 6.8 \\
\hline
\end{tabular}

RP: retained placenta.

cattle and fed a total mix ratio. All cows were milked twice daily.

\section{Case definition}

All cows were checked for body condition score, RP, and periparturient diseases as well as abnormal partus including dystocia, twins, and stillbirths. Dystocia was defined as calving difficulty resulting from prolonged spontaneous calving or prolonged or severe assisted extraction. Stillbirths included calves born dead or those that died within $24 \mathrm{~h}$ after birth. RP was considered as a failure to expel the fetal membrane within $24 \mathrm{~h}$ of calving $[8,10]$. Metritis was defined as a condition causing systemic signs of illness (e.g., fever, anorexia, or decreased milk production), characterized by a foulsmelling, brown-red, watery vaginal discharge occurring within the first 21 days in milk (DIM) [11]. Endometritis was defined as chronic uterine inflammation without systemic illness occurring 21 DIM, diagnosed by clinical or ultrasound examination. Pyometra was defined as the accumulation of purulent or mucopurulent exudate in the uterus within 63 DIM.

Cows were checked daily by farm managers and veterinarians for postpartum diseases and monitored for mastitis and metabolic disorders including milk fever, ketosis, and abomasal displacement. Milk fever was diagnosed by the presence of clinical signs (weakness, abrupt milk yield drops, and not standing) and sera chemistry analysis. Ketosis was also defined by the presence of clinical sings (anorexia, depression and nerves) and sera chemistry analysis. 
Table 3. The occurrence of postpartum diseases in dairy cows with retained placenta within 60 DIM

\begin{tabular}{|c|c|c|c|c|c|c|c|c|c|c|}
\hline \multirow{2}{*}{ Diseases } & \multirow{2}{*}{ No. of RP- } & \multicolumn{9}{|c|}{ Duration of placental retention (days) } \\
\hline & & 2 & 3 & 4 & 5 & 6 & 7 & 8 & 9 & 10 \\
\hline Metritis & 15 & 1 & 1 & & 3 & 1 & 2 & 4 & 1 & 2 \\
\hline Endometritis & 5 & 1 & & & 2 & 1 & & & 1 & \\
\hline Pyometra & 4 & & & & & & 1 & 1 & 1 & 1 \\
\hline Mastitis & 9 & & 1 & 1 & 2 & & 2 & & 1 & 2 \\
\hline Pneumonia & 1 & & & & 1 & & & & & \\
\hline Ketosis & 1 & & & & & & & & 1 & \\
\hline Milk fever & 1 & & & & & & 1 & & & \\
\hline Foot rot & 2 & & 1 & & & & & & & 1 \\
\hline Complex & 2 & & & & & 1 & & & & 1 \\
\hline Total & 40 & 2 & 3 & 1 & 8 & 3 & 6 & 5 & 5 & 7 \\
\hline
\end{tabular}

DIM: days in milk.

Table 4. The occurrence of postpartum diseases and culling in cows with retained placenta by parity

\begin{tabular}{ccccc}
\hline \hline \multirow{2}{*}{ Parity } & \multicolumn{3}{c}{ No. of RP } & \multicolumn{2}{c}{ No, of culling in RP+ } \\
\cline { 2 - 5 } & Total & PD $(+)^{*}(\%)$ & Total & 3 \\
\hline 1 & 21 & $15(71.4)$ & 3 & 2 \\
2 & 18 & $14(77.7)$ & 3 & 2 \\
3 & 9 & $3(33.3)$ & 7 & 5 \\
4 & 16 & $8(50.0)$ & 16 & 12 \\
Total & 64 & $40(62.5)$ & & 3 \\
\hline
\end{tabular}

RP: retained placenta, ${ }^{*} \mathrm{PD}$ : postpartum diseases.

\section{Results}

Data from 456 cows were evaluated in this study. The incidence rates of dystocia, twins, stillbirths and RP were 21.9, 2.6, 12.3 and 14.0\%, respectively (Table 1). RP occurred in 64 cases, of which 21 (11.5\%), 18 (14.2\%), $9(12.3 \%)$ and $16(21.9 \%)$ were first, second, third, and fourth and higher parity, respectively.

The duration of RP was 2 to 15 days (Table 2) with an overall mean of 6.8 days. When broken down by number of births, fourth and higher parity had a mean RP of 10.5 days with means of 6.1, 7.4, and 6.1 days for first, second, and third parity cases, respectively.

A total of $63 \%$ of dairy cows with RP had postpartum diseases (Table 3); 23.4\% developed metritis, and of those, $35.3 \%$ developed endometritis or pyometra.

A total of 16 cows with RP were culled within 60 DIM (Table 4), of which 12 had postpartum diseases while only 4 cows without postpartum diseases were culled during the same time.

\section{Discussion}

The NLRI dairy herd evaluated in this study is a closely monitored experimental group. Therefore, the results obtained may not be representative of commercial herds. However, the advantage of studying this data set is that it provides detailed information from the same herd having regular management and feeding systems over a three year period.

In this study, the 14\% RP incidence rate was higher than that of other studies which reported $7.8 \%$ [7] and $8.6 \%$ [10], but similar to that documented by Han and Kim [8]. Comparing the annual incidence of RP, among the 64 cases, $35(21.5 \%)$ occurred in 2008, $15(10.1 \%)$ in 2009, and $14(9.7 \%)$ in 2010. The incidence of RP in 2008 was double that of the other years evaluated. Annual differences in RP incidence rates may be affected by forage and silage harvests due to bad weather conditions at the time. Han and Kim [8] suggested that high rates of RP may also be related to farm management and inadequate nutrition. Results of this study 
indicated that RP was not associated with abnormal partum but highly associated with twins. This result was different to the results of Sheldon [12] and Han and Kim [8], which indicated that dystocia and twins present higher risks for developing RP and metritis.

The mean duration of RP was 6.8 days in this study which was similar to published information indicating that membranes are retained for seven days on average in RP cases [6]. However, fourth and higher parity dairy cows had a greater mean duration of placental retention (10.5 days) than those of lesser parity. These results indicate that incidence rates and duration of RP increase with parity which is in accordance with van Werven et al. [14] who reported that the incidence rate and duration of RP was strongly influenced by parity.

A total of $63 \%$ of RP cases developed postpartum diseases including reproductive and metabolic disorders, mastitis, and others. Among cases with postpartum disease, over $37 \%$ with RP developed reproductive disorders including metritis, endometritis, and pyometra, and two cases of postpartum diseases were complicated by metritis and mastitis. Other studies $[8,10]$ reported similar results of $25 \sim 50 \%$ and less than $78.9 \%$ of cows with RP developing metritis. LeBlanc et al. [10] reported the largest risk factor for metritis to be RP, but other conditions that may impair feed intake and immune function also increase the risk of metritis. RP is also associated with an increased risk of subsequent ketosis, abomasal displacement, and mastitis [4, 7, 13]. However, the occurrence of metabolic disorders in this study was not greater in the RP group. Only two cases of cows with RP developed metabolic disorders and 11 developed mastitis. It is assumed that disease status results may be different for cattle from commercial farms.

During the study period, the average culling rate per year was $47 \%$ with $52 \%$ culling before the fourth lactation. Bascom and Young [1] concluded that the optimum culling rate for farm profitability is between 25 and $30 \%$ but the NLRI herd is out of that range due to the fact that it is an experimental group. A total of 16 cows with RP were culled within 60 DIM and $43.7 \%$ of culled cows $(n=7)$ were of fourth or higher parity. Most of these cows (75\%) suffered from postpartum diseases. Only four cows without postpartum diseases were culled during the same time. It was assumed that cows with RP are more at risk of culling than those without RP. Study results were different than those reported by Dubuc et al. [4] which reported that culling risks at 30 and 63 DIM were unaffected by RP and metritis.

The results of this study suggest that there is a very close relationship between RP and postpartum diseases in dairy cattle after calving. RP increases risks for postpartum diseases such as metritis and mastitis, and culling hazards up to 60 DIM.

\section{Acknowledgments}

This work was carried out with the support of the "Cooperative Research Program for Agriculture Science \& Technology Development (Project No. 200901OFT 072250454)" Rural Development Administration, Republic of Korea.

\section{References}

1. Bascom SS, Young AJ. A summary of the reasons why farmers cull cows. J Dairy Sci 1998, 81, 22992305.

2. Beagley JC, Whitman KJ, Baptiste KE, Scherzer J. Physiology and Treatment of Retained Fetal Membranes in cattle. J Vet Intern Med 2010, 24, 261-268.

3. Bell MJ, Wall E, Russell G, Roberts DJ, Simm G. Risk factors for culling in Holstein-Friesian dairy cows. Vet Rec 2010, 167, 238-240.

4. Dubuc J, Duffield TF, Leslie KE, Walton JS, LeBlanc SJ. Effects of postpartum uterine diseases on milk production and culling in dairy cows. J Dairy Sci 2011, 94, 1339-1346.

5. Dubuc J, Duffield TF, Leslie KE, Walton JS, LeBlanc SJ. Risk factors for postpartum uterine diseases in dairy cows. J Dairy Sci 2010, 93, 57645771.

6. Eiler H, Fecteau KA. Retained placenta. In: Youngquist RS, Threlfall WR (eds.). Current Therapy in Large Animal Theriogenology. 2nd ed. pp. 340-348, Saunders, Philadelphia, 2006.

7. Goff JP. Major advances in our understanding of nutritional influences on bovine health. J Dairy Sci 2006, 89, 1292-1301.

8. Han IK, Kim IH. Risk factors for retained placenta and the effect of retained placenta on the occurrence of postpartum diseases and subsequent reproductive performance in dairy cows. J Vet Sci 2005, 6, 53-59.

9. Laven RA, Peters AR. Bovine retained placenta: 
aetiology, pathogenesis and economic loss. Vet Rec 1996, 139, 465-471.

10. LeBlanc SJ. Postpartum uterine disease and dairy herd reproductive performance: a review. Vet J 2008, 176, 102-114.

11. Sheldon IM, Lewis GS, LeBlanc S, Gilbert RO. Defining postpartum uterine disease in cattle. Theriogenology 2006, 65, 1516-1530.

12. Sheldon IM. The postpartum uterus. Vet Clin North Am Food Anim Pract 2004, 20, 569-591.
13. Trevisi E, Ferrari AR, Bertoni G. Productive and metabolic consequences induced by the retained placenta in dairy cows. Vet Res Commun 2008, 32 (Suppl 1), S363-366.

14. van Werven T, Schukken YH, Lloyd J, Brand A, Heeringa HTJ, Shea M. The effects of duration of Retained Placenta on reproduction, milk production, postpartum disease and culling rate. Theriogenology 1992, 37, 1191-1203. 